Das Filtrat wird am besten in farblosen Glas-Cylindern, wie sie für colorimetrische Bestimmungen üblich sind, gesammelt. Mit einiger Uebung gelingt es, die Endreaction in höchstens drei oder vier Versuchen zu erhalten, so dass eine solche Bestimmung nach Bereitung der Lösungen nicht mehr als 10 Minuten in Anspruch nimmt. Der Werth eines und desselben Farbstoffes steht natürlich im umgekehrten Verhältnisse zu der Anzahl Cubikcentimeter, die zur Fällung einer gegebenen Menge Nachtblaulösung erforderlich ist. Die Reaction ist eine äusserst empfindliche; es genügt zum Beispiel ein einziger Tropfen der erwähnten Pikrinsäurelösung im Ueberschuss, um im Filtrate eine deutliche Gelbfärbung hervorzubringen.

Das im Handel als Krystallviolett bekannte Chlorhydrat des Hexamethylpararosanilins verbindet sich ebenfalls mit Pikrinsäure zu einer unlöslichen Verbindung, der die Formel $\mathrm{C}_{25} \mathrm{H}_{31} \mathrm{~N}_{3} \cdot \mathrm{C}_{6} \mathrm{H}_{2}\left(\mathrm{NO}_{2}\right)_{3} \mathrm{OH}$ zukommt, und kann deshalb auch zur quantitativen Pikrinsäurebestimmung benutzt werden.

Selbstverständlich lassen sich diese Reactionen auch zur Bestimmung des Nachtblaus und des Krystallvioletts gebrauchen.

Eine neue Methode der mikroskopischen Papierprüfung gründet Fr. v. Höhne ${ }^{*}$ ) auf die Unterscheidung der drei Hauptgruppen von Papierfasern, nämīich 1) der alten Hadernfasern (Leinen, Hanf, Baumwolle), 2) der besseren, wesentlich aus Cellulose bestehenden Ersatzstoffe (Holzcellulose, Strobcellulose, Espartofaser) und 3) der schlechten ververholzten Ersatzstoffe (Holzschliffe, Jute) durch die Färbungen derselben mit Jod und Schwefelsäure. Leider gibt Verfasser bezüglich der Hauptsache, nämlich der Dichte der anzuwendenden Schwefelsäure nur an, dass dieselbe eine ganz bestimmte sein und durch praktische Versuche ermittelt werden müsse. $\mathrm{Zu}$ diesem $\mathrm{Zwecke}$ nimmt man aus weissen Hadern etwas Baumwolle und Leinenfasern, ferner etwas weisse Holzcellulose und weissen Strohstoff, kocht diese Fasern gemeinschaftlich einige Minuten in $1-5$ procentiger Kalilauge, wäscht die Lauge aus und bringt von jeder Faser sehr kleine Mengen neben einander auf Objectträger, so dass jedes Präparat aus den vier genannten Fasern besteht. Wichtig ist, dass die Fasern keine Bündel oder Knäuel bilden, sondern stets sorgfältig mit der Nadel von einander getrennt werden. Nachdem man durch zweimaliges starkes Andrücken von Filtrirpapier das überschüssige Wasser entfernt hat, setzt man zu den Fasern einen Tropfen

*) Mittheil. d. k. k. Gewerbe-Museums zu Wien, durch Chemiker-Ztg. 13, 155. 
Jod-Jodkaliumlösung*), welcher die Fasern ganz bedecken soll. Nach 1-2 Minuten langer Einwirkung nimmt man die Lösung durch zweimaliges Abdrücken mit Filtrirpapier vollständig wieder fort, so dass keine Jodlösung sich mehr zwischeu den Fasern befindet. Das so mit Jodlösung behandelte, aus 4 Fasern bestehende Präparat wird nun mit einem Tropfen Schwefelsäure bedeckt, worauf man das Deckglas auflegt. Die Schwefelsäure muss man so weit verdünnen, dass sich bei dieser Behandlung Baumwolle, Flachs, Hanf schön rothviolett, Holzcellulose und gewöhnliche Strohcellulose rein blau oder graublau färben. Hat man sich die Schwefelsäure richtig eingestellt, so bietet die Unterscheidung der Papierfasern keine Schwierigkeiten.

Die Methode kann für die gewöhnlichen, weissen, besseren Papiere, welche, wie das deutsche und österreichische Fabrikat, fast nie Espartooder Maisfasern enthalten, ohne Weiteres angewendet werden und gibt in der Regel ganz sichere Ergebnisse. In diesen Papieren färben sich ausnahmslos Baumwolle, Hanf, Flachs, weissgebleichte Jute, Chinagras und Papiermaulbeerbaum rothviolett, Holz- und gewöhnliche Strohcellulose rein blau, Holzschliff und ungebleichte Jute dunkelgelb. Enthalten die Papiere Esparto- oder Maisfasern (welche leicht zu erkennen sind) so soll man etwas concentrirtere Schwefelsäure anwenden, oder eine kurze Vorbehandlung mit Salpetersäure geben.

Das Verfahren gilt nur für die Fasern in Feinpapieren. Rohfasem and Grob-Papiere, in welchen die Fasern nicht schon starke Bleichung erlitten haben, verhalten sich theilweise ganz anders.

\section{Ein Verfahren zur quantitativen Bestimmung des Holzschliffes} im Papier gründen R. Godeffroy und M. Coulon***) darauf, dass Cellulose, welche mit Wasser, Alkohol und Aether ausgekocht ist, beim Kochen mit verdünnter Goldchloridlösung letztere nicht reducirt, während Holzschliff stark reducirend wirkt. $100 \mathrm{~g}$ des letzteren (völlig getrocknet) schieden bei gleicher Behandlung 14,285 $g$ Gold ab.

Bei Untersuchung von Papieren wird die genau gewogene Probe zur Beseitigung der Leimung zuerst mit kaltem, dann mit siedendem Wasser und schliesslich zur Entfernung der Thonerde mit einer siedenden

*) Dieselbe muss so concentrirt sein, dass eine etwa $3 \mathrm{~cm}$ dicke Schicht rubinroth und dabei klar und durchsichtig erscheint.

**) Mittheil. d. technolog. Gewerbe-Museums zu Wien, durch Zeitschr. d. Allg. Oesterr. Apotheler-Vereines 27, 21. 